\title{
Study of springback pattern of non-uniform thickness section based on V-bending experiment
}

\author{
A. F. Adnan, A. B. Abdullah* and Z. Samad \\ Metal Forming Research Laboratory, School of Mechanical Engineering \\ Universiti Sains Malaysia, 14300 Nibong Tebal, Pulau Pinang, Malaysia. \\ *Corresponding author: mebaha@usm.my \\ Phone: +604-5996332
}

\begin{abstract}
Non-uniform thickness section is one of most effective approaches in reducing automotive part weight. Less weight results in less fuel consumption and therefore good for the environment. Formability is the main issue of non-uniform thickness section, since changes in thickness may cause parts to behave distinctively compared to uniform thickness during the forming process. One of the main concerns is the springback pattern. This study focused on springback behaviour of AA6061 strip with non-uniform thickness through V-bending experiment. The outcome will contribute in the manufacturing of automotive parts with non-unifrom thickness, where defects such as springback can be predicted and minimised. In the experiment, three parameters i.e. thickness ratio, bend radius and alignment were studied and the effects were observed. The result found that thickness was the most influential parameters compared to others. Thickness was reduced through cold deformation, causing the hardness to increase and then resulted in higher springback value. The effect of alignment was almost negligible. Validation made based on the result found is in agreement with prior published works.
\end{abstract}

Keywords: Weight reduction; non-uniform thickness; springback; thickness ratio.

\section{INTRODUCTION}

Nowadays, $96 \%$ of the world's transportation systems depend on petroleum-based fuels and products, with the global transportation system accounting for about $40 \%$ of the world's oil consumption of nearly 75 million barrels of oil per day [1]. Lightweight contruction is one of the technologies applied in the industry to reduce vehicle weight. Lightweight components can be achieved either by use of light materials or by design strategies via the forming process [2]. Formability of the material depends on many factors including thickness, material properties and complexity of the part's geometry. The most common problem faced in the stamping of sheet metal is uncontrolled springback. Lately, efforts are made to improve the sheet metal manufacturing process and forming capability. However, not all of the processes are able to produce complex shapes. To overcome these challenges, semi-finished products or also known as tailored blanks are increasingly becoming a favourite to manufacturers. Tailored blanks provide a weight reduction potential of 20-34\%. Tailored blank is the collective for semi-finished sheet products which are charecterised by a local variation of the thickness, sheet material, coating and material properties [3]. Tailored blanks can be divided into four sub-groups; tailor welded blanks, patchwork blanks, tailor rolled blanks and tailor heat treated blanks 
[4]. Figure 1 shows the potential weight reduction via tailor roller blanks as proven by Meyer et al., [5].

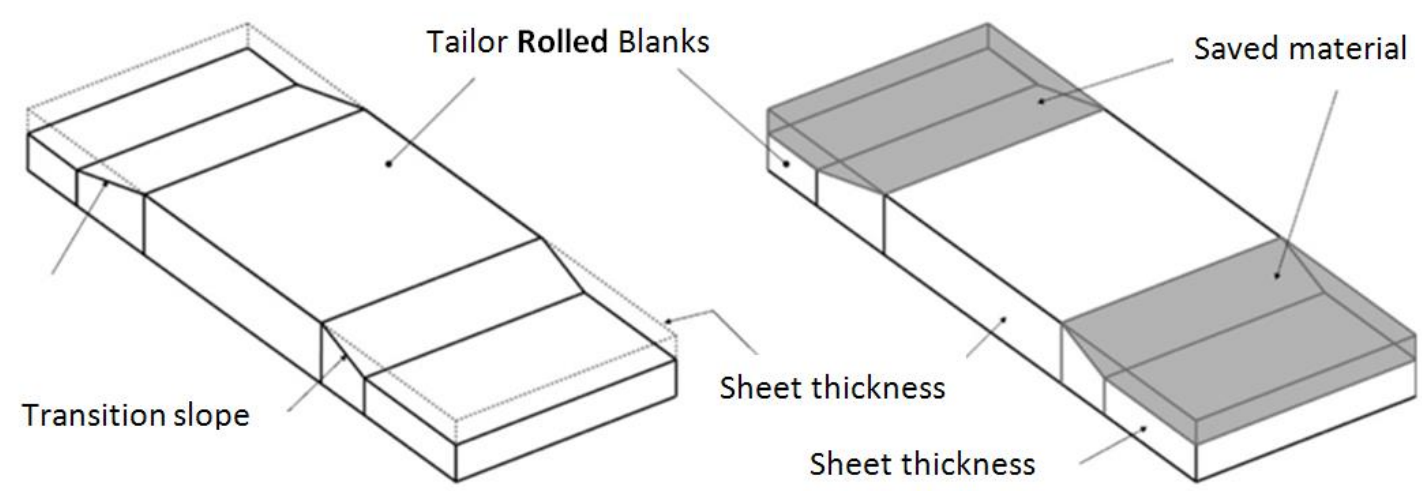

Figure 1. Sheet with constant thickness compared with the TRB with optimised thickness distribution [5].

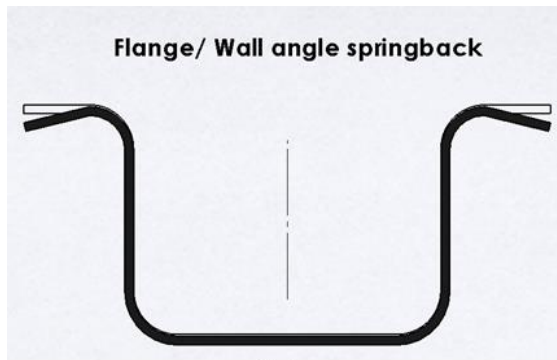

(a)
Sidewall curl springback

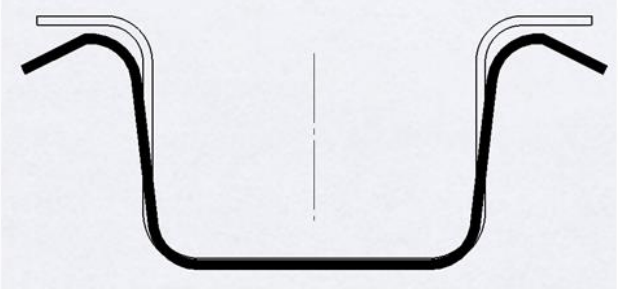

(b)

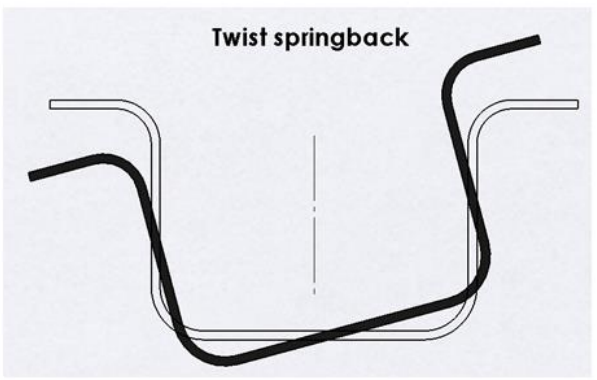

(c)

Figure 2. Schematic illustrations of some common springback modes in automotive part.; a. Flange/wall angle change, b. Sidewall curl, c. Twist springback. The dark line represents the shape after springback and the light line is the design intent [6].

Springback is one of the major geometrical variation issues in metal forming. For example, the inner and outer panels can strongly affect the quality of final stamping [7]. Springback is a common phenomenon in sheet metal forming which is mainly caused by the elastic recovery and redistribution of internal stress during the unloading process [8] and it is inevitable [9]. Nie et al. [10] combined electrical heating and cyclic deformation in their study to achieve zero springback in forming super alloy such as Titanium alloy. Aso and lizuka [11] introduced lump-punch penetration to reduce springback and achieve the correct bend angle. Yoshida [12] classified springback into three modes; flange/wall angel change, sidewall curl and twist, while Eggertsen and Mattiasson [6] represented 
these types of springback in automotive parts as illustrated in Figure 2. Springback pattern for uniform thickness section can easily be predicted and minimised as there are many researches on other parameters that have conducted before. Abdullah and Samad [13] studied the effect of bend location to springpack pattern. Other parameters include punch radius, holding force[14], thickness [15, 16], die radius [17], punch angle [18], velocity [19], rolling direction [20] and die gap [17]. The studies were performed using various methods and tools, such as ANN [19, 21], analytical [22], experimental [23] and finite element simulation [24, 25]. Ling et al., [26] and Abdullah et al, [21] extended their studies by optimising the parameters using the Taguchi Method. Karaagac [27] studied the springback using the flexforming process. Other than V-bending, springback has also been studied using Z-bending [24] and U-bending [16]. In improving the accurcay of simulation result, Fang et al., [9] have taken into consideration the grain heterogeneity in their study. In another case, Peng et al., [28] studied springback pattern on laminated steel sheet via simulation and experiment. Similar approach was carried out by Yazdani et al., [16] for a two-layer sheet made of pure copper and 304 stainless steel.

All of these studies focus on uniform sheet thickness, and there is still a lack of work done on non-uniform thickness. This is because as the thickness varies, springback may behave differently and become much more difficult to be predicted and controlled, thus requiring further study. Therefore, the main objective of this paper is to investigate the effect of a few parameters such as thickness ratio, bend angle and allignment to the springback pattern of AA6061 strip via the V-bending method. A study of springback pattern on non-uniform thickness section will benefit the automotive industry in the manufacturing of parts.

\section{METHODS AND MATERIALS}

\section{Specimen Preparation}

For this experiment, the aluminium strip has to be cold formed into non-uniform profile (tapered shape) as shown in Figure 3, which has various thicknesses and the data are summarised in Table 1. For the deformation, the die and puncher were made from D2 steel material and the process was performed using the 100 tone mechanical press machine as shown in Figure 4(a) and cut to the desired dimension by using a wirecut EDM machine as shown in Figure 4(b). The preparation of specimen began with the process of thickness reduction for aluminium strip with the dimension of $65 \mathrm{~mm}$ width, $80 \mathrm{~mm}$ length and $3 \mathrm{~mm}$ thickness as shown in Figure 5(a) and cut into the desired dimension at $50 \times 20 \mathrm{~mm}$ as shown in Figure 5(b). There were six sets of specimen with different thickness ratios as listed in Table 1. Here, thickness ratio can be defined as a ratio of minimum thickness of the strip after deformation at one edge to the maximum thickness at the other edge as shown in Figure 3.

Table 1. Aluminium strip data.

\begin{tabular}{cccc}
\hline Set & Length $(\mathrm{mm})$ & Wide $(\mathrm{mm})$ & Thickness ratio \\
\hline 1. & 50 & 20 & 0.950 \\
2. & 50 & 20 & 0.923 \\
3. & 50 & 20 & 0.902 \\
4. & 50 & 20 & 0.881 \\
5. & 50 & 20 & 0.859 \\
6. & 50 & 20 & 0.838 \\
\hline
\end{tabular}




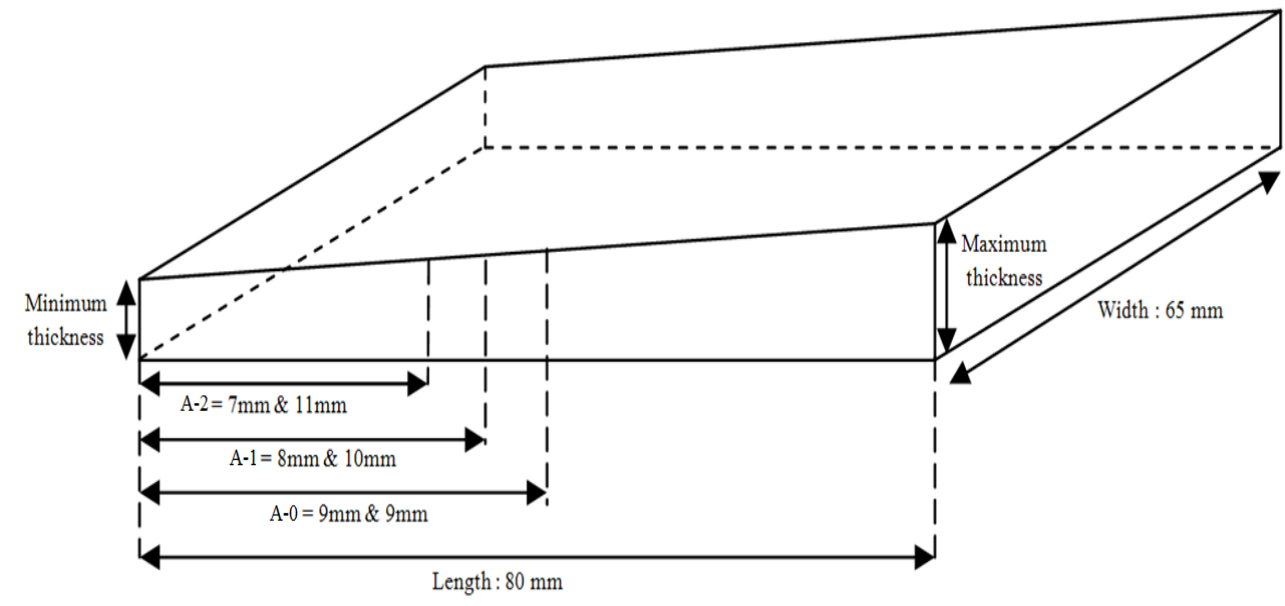

Figure 3. Aluminium strip for non-uniform profile (tapered shaped).

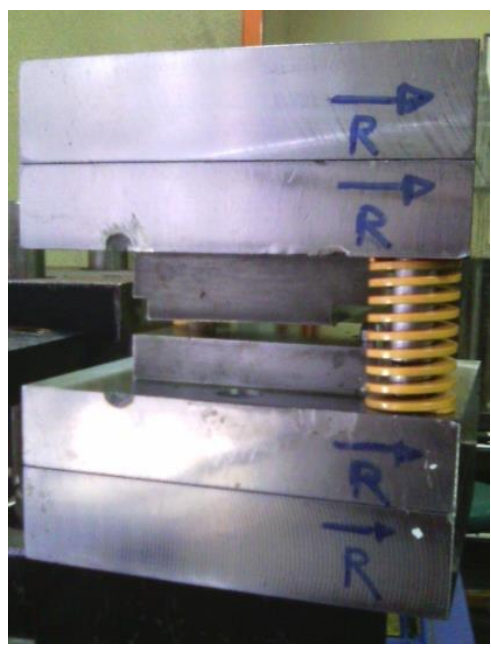

(a)

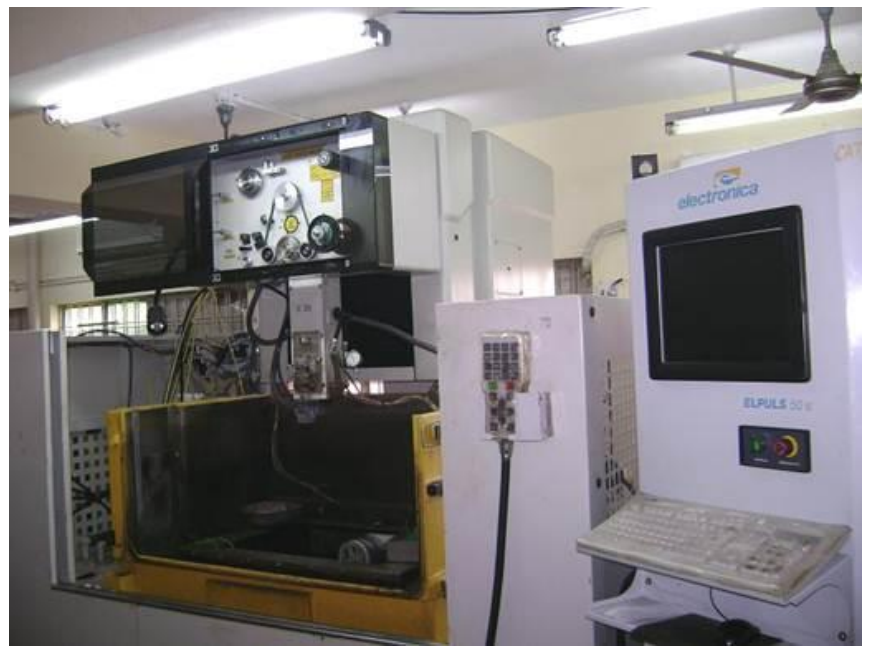

(b)

Figure 4. Setup for the specimen preparation; a) die set for preparation of thickness reduction by cold forming, b) specimen cutting using wirecut EDM.

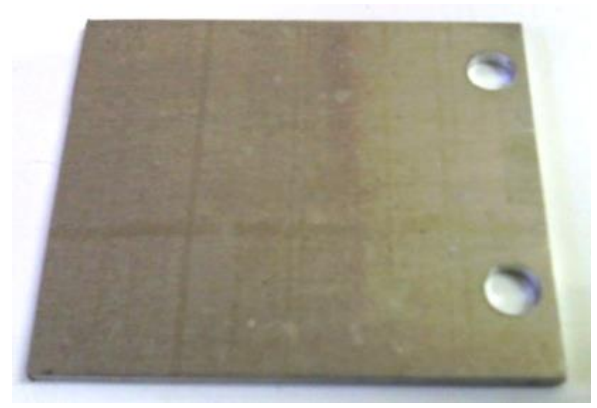

(a)

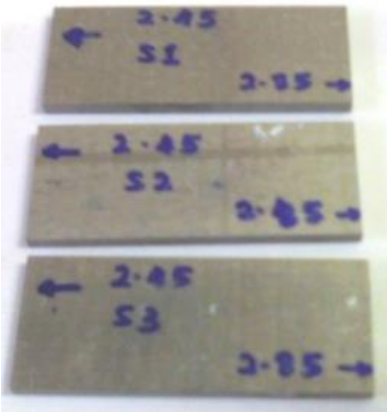

(b)

Figure 5. Aluminium strip (a) after deformation and (b) after cutting with dimension of $20 \mathrm{~mm} \times 50 \mathrm{~mm}$. 


\section{Experiment Setup}

In this experiment, the springback pattern will be observed based on the variation of bend angle, thickness ratio and alignment of the workpiece. The setup of the V-bending experiment on the UTM Instron 3367 and geometry of the V-bending die are shown in Figure 6(a) and (b), respectively. The speed was set at the lowest speed to observe the changes and at a constant speed i.e. at $5 \mathrm{~mm} / \mathrm{s}$. Bend angle can be obtained according to the punch travel or stroke. Meanwhile, alignment is described as a point of where the punch pointed at the specimen during the bending process as shown in Figure 3, where A0, A-1 and A-2 represent the locations where the punch was pointed at during Vbending. In the measurement of angle after loading, the die valley radius, punch radius and the die opening were constant at $90^{\circ}, 2 \mathrm{~mm}$ and $32 \mathrm{~mm}$, respectively as shown in Figure 7(. The Rax Vision Mitutoyo Profile Projector (PC 3000) machine was used in the measurement of the angle of bent specimen after unloading. The two lines technique was applied to measure the angle as shown in Figure 8. The two lines technique required two points for first single line and two points for the second line. Profile projector then calculated the angle between the two lines.

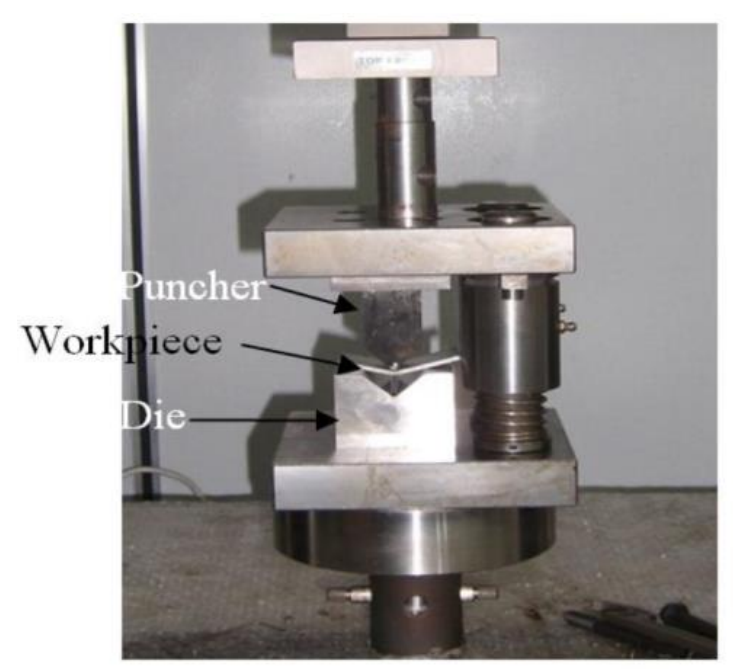

(a)

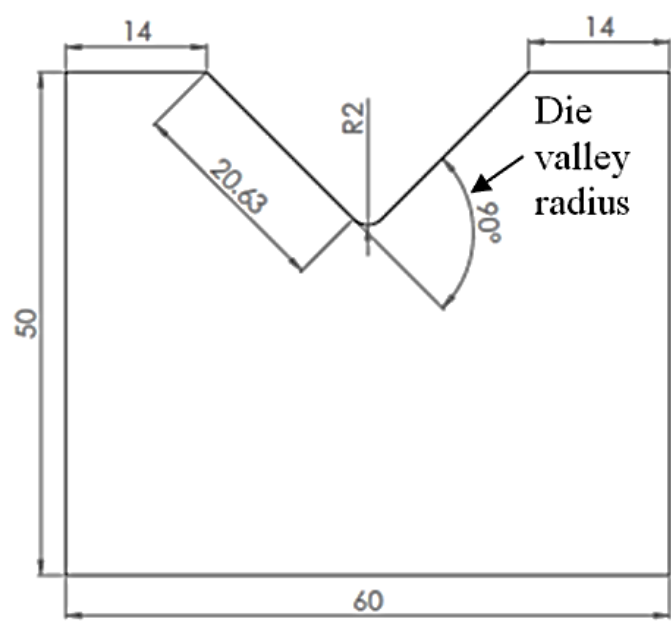

(b)

Figure 6. (a) V-bending experimental setup, (b) V-bending die geometry.

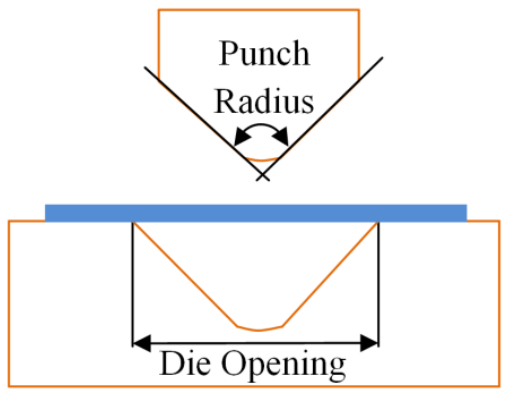

(a)

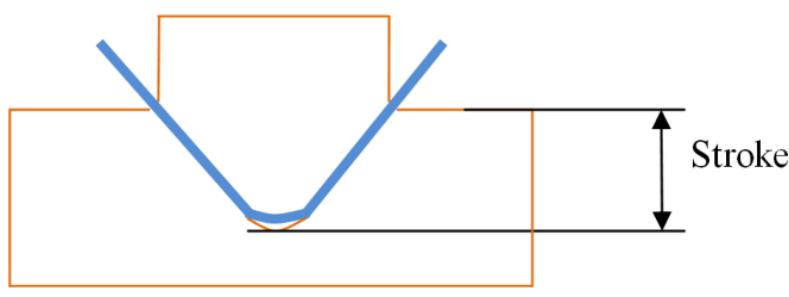

(b)

Figure 7. The definition of v-bending process. (a) initial and (b) end. 


\section{Springback Measurement}

Next, springback can then be determined by the difference between angle after loading and angle after unloading..

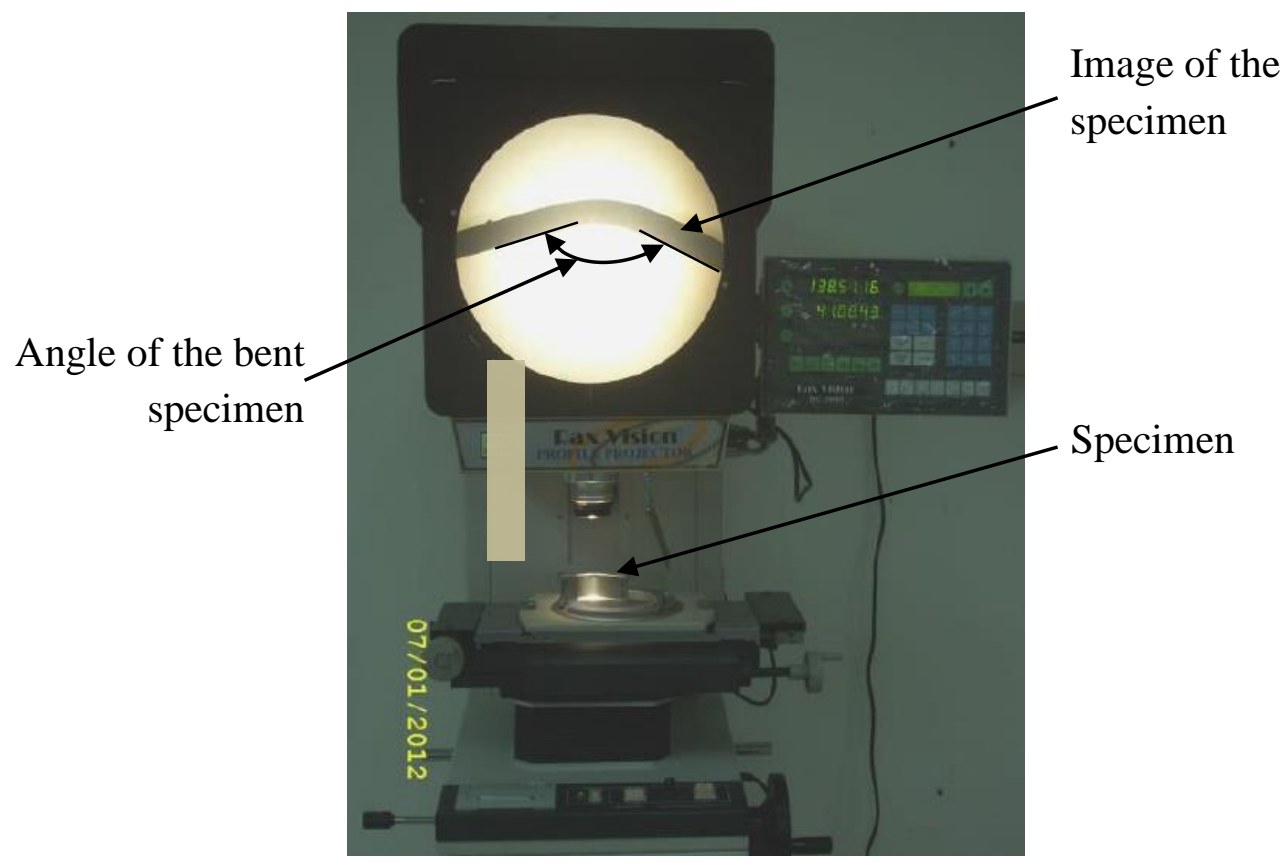

Figure 8. Springback measurement using Profile Projector

\section{RESULTS AND DISCUSSION}

The amount of springback is generally defined as the difference between the angle after loading and after unloading. In this case, stroke values play an important role in springback measurement after loading condition. In the V-bending experiment, observations were made at different strokes. The bend radius and stroke were at 10, 17 and 24 degrees and 3,5 and $7 \mathrm{~mm}$, respectively. The initial thickness of the strip was 3 $\mathrm{mm}$ and the maximum stress was required to perform the bending till the end of the stroke was approximately $700 \mathrm{MPa}$. Figure 9 shows the stress strain behaviour of the material during V-bending. An Instron 3367 Universal Tensile Machine was used to perform the bending process. Cold deformation result in work-hardening characteristics caused the metal to become harder and stronger [29]. This, in fact, explained why the flow stress increased as the amount of axial strain was increased. Figure 10 shows the relation between thickness of workpiece and Vickers hardness number measure along the longitudinal direction of the strip. As the thickness reduced due to strain, hardness will increase. Furthermore, strain also played a significant role in the springback results where the increasing hardening was due to strain and will increase the springback [23, 30, 31]. Figure 11 shows the strain hardening index, $n$ versus the precentage of springback taking the minimum thickness, $t$ as the parameter to be studied. The lowest thickness i.e 2.45 $\mathrm{mm}$ produced the highest percentage of springback compared to others. This may cause strain hardening to occur as it involves the highest strain. 


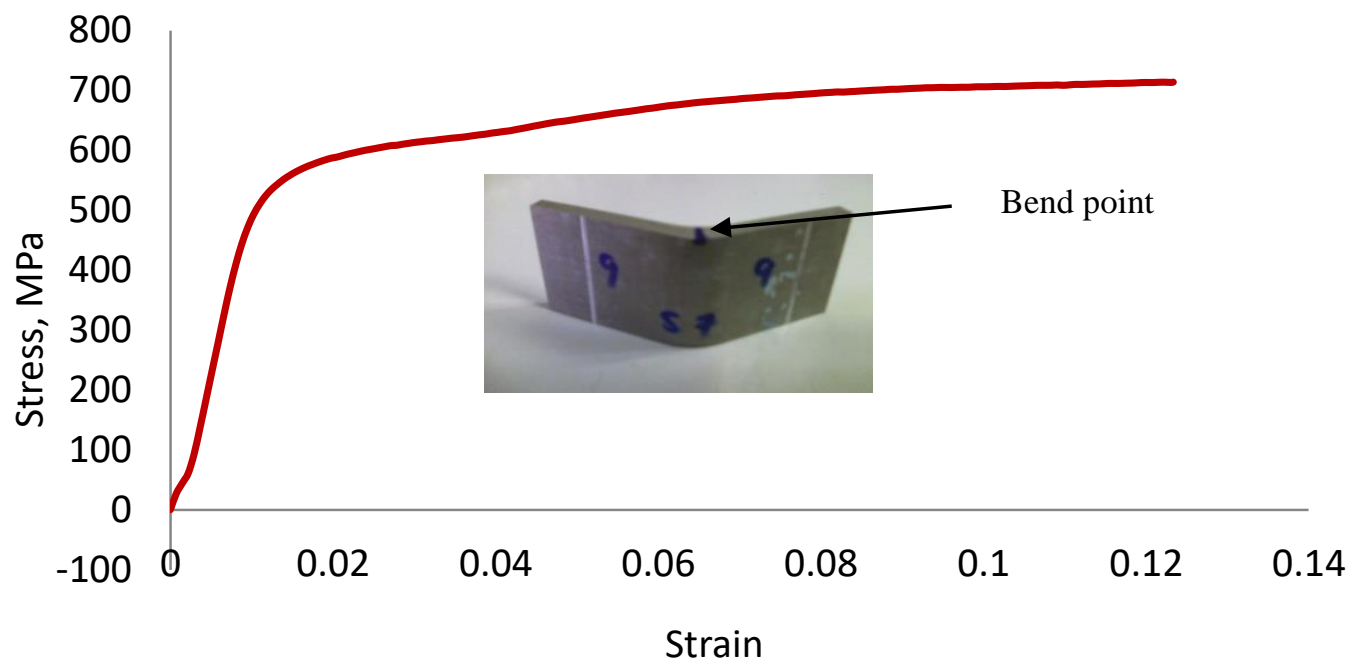

Figure 9. The stress strain behaviour of the material.

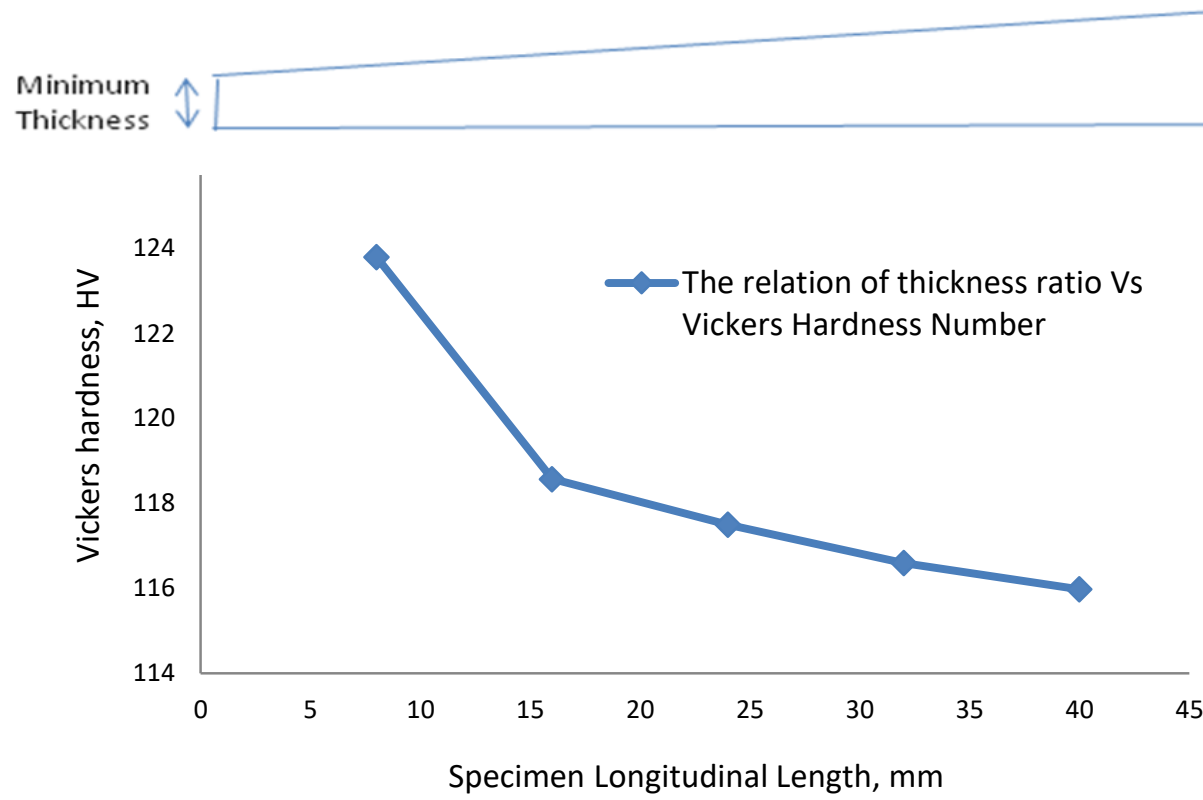

Figure 10. The relation of Thickness Vs Vickers Hardness Number.

Figure 12(a) to (c) present the effects of the minimum thickness and bend angle to the springback at different alignments. From the results, it is shown that the alignment value affected the springback. The patterns showed a consistent pattern, even though there were minor differences between each specimen. In this case, it can be stated that the closer the alignment (punch point) to the centre of strip, the more consistent the springback value and will reduce the springback. At alignment of $7 \mathrm{~mm}$ as shown in Figure 12, the effect of alignment was minimal compared to the effect of the bend angle. Otherwise, at a more stable alignment, the pattern was the same but the point seemed to be more persistent and the result showed a significant difference between the effects of alignment and effects of bend angle. The results presented in this paper are in agreement with the studies that have been done by Garcia-Romeu et al. [32]; Ouakdi et al [30]; Abdullah and Samad [33] and Zhang [34]. 


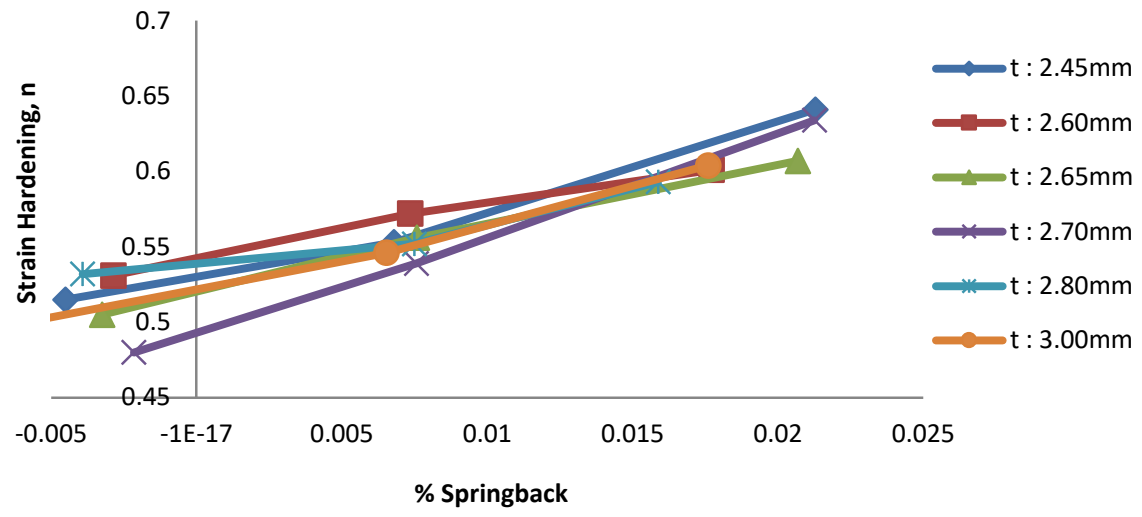

Figure 11. Strain hardening index, $\mathrm{n}$ versus \% springback taking minimum thickness, $t$ as a parameter.

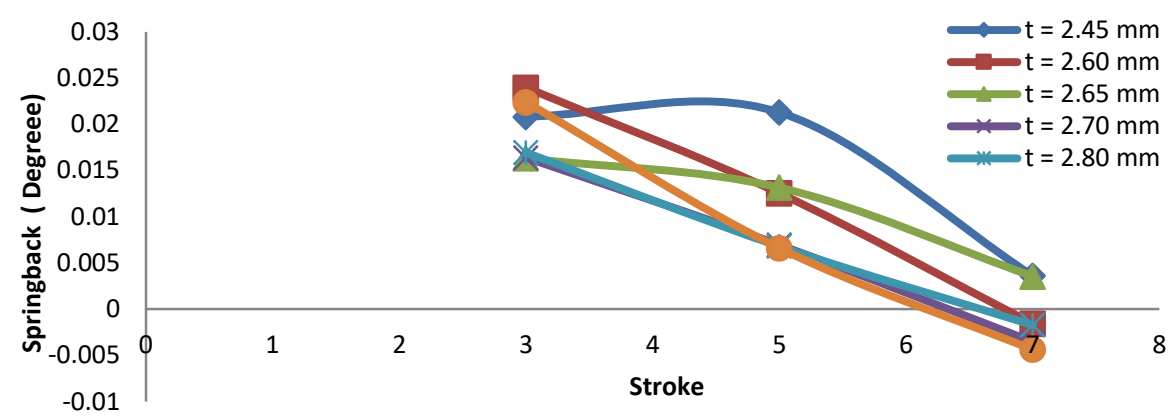

(a)

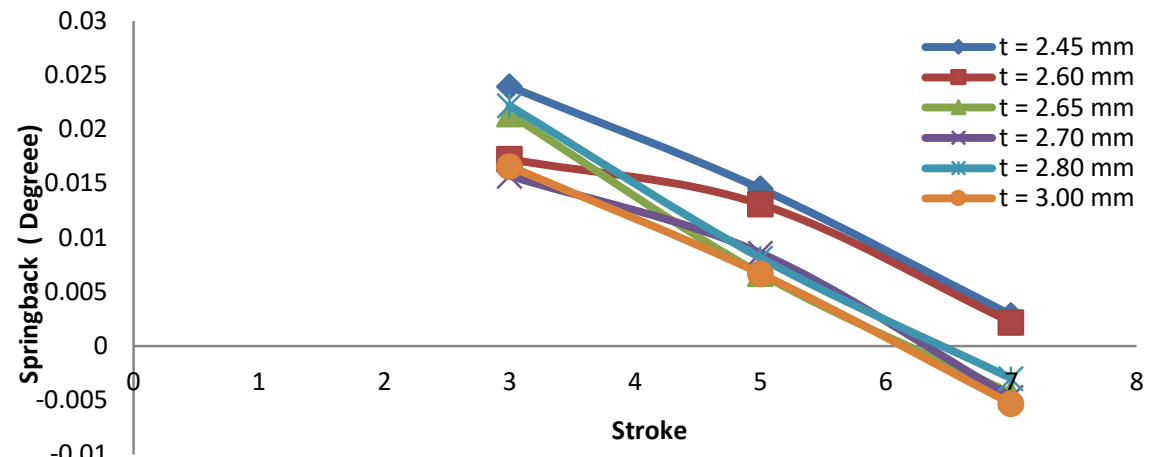

(b)

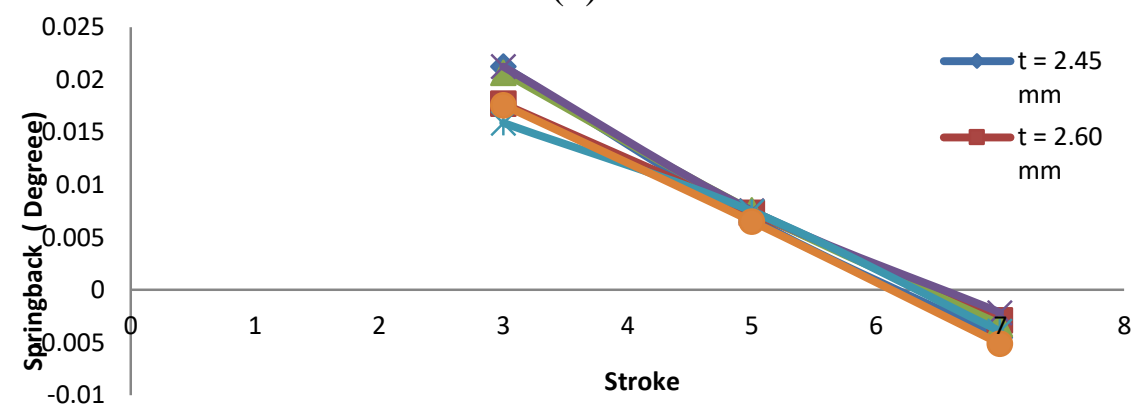

(c)

Figure 12. The springback behaviour at various minimum thicknesses for alignment (a) $9 \mathrm{~mm}$ and $9 \mathrm{~mm}$, (b) $8 \mathrm{~mm}$ and $10 \mathrm{~mm}$ and (c) $7 \mathrm{~mm}$ and $11 \mathrm{~mm}$. 


\section{CONCLUSIONS}

The study has presented the experimental investigation on springback behaviour of Aluminium 6061 strip with non-uniform thickness. Several experiments have been conducted on the effects of thickness, alignment, and bend angle. From the analysis of the results obtained, it can be concluded that the springback was affected by the changes in thickness and bending angle. At different thickness ratios, the results obtained showed the nature of variation of springback (\%) with the change in the thickness ratio. From the results, springback percentage higher in the case of higher strain hardening index, and the springback percentage decreased with the increase of strip thickness. Meanwhile, the effect of the alignment had little influence on the value of springback. From this finding, manufacturers in the automotive industry may get benefits as their problem of unpredicted and uncontrolled springback where forming the part with non-uniform section can be solved. For future work, the springback behaviour of the aluminium strip with various non-uniform thickness profiles will be further explored. Data and information in this study are very useful to be used as reference in future research and to be used as a platform to understand the behaviour of springback and the parameters that influence the springback.

\section{ACKNOWLEDGEMENTS}

The author would like to acknowledge the Universiti Sains Malaysia and Ministry of Higher Education through Fundamental Research Grant Scheme (AC No. 203/PMEKANIK/6071308) for sponsoring this research. The authors also want to thank Mr. Fakuruzi for his assistant in conducting the test.

\section{REFERENCES}

[1] Mayyas A, Qattawi A, Omar M, Shan D. Design for sustainability in automotive industry: A comprehensive review. Renewable and Sustainable Energy Reviews. 2012;16:1845-62.

[2] Jeya GR, Vinodh S. Application of fuzzy VIKOR and environmental impact analysis for material selection of an automotive component. Materials \& Design. 2012;37:478-86.

[3] Sahaya-Anand TJ. Nickel as an Alternative Automotive Body Material. Journal of Mechanical Engineering and Sciences. 2012;2:187-97.

[4] Merklein M, Johannes M, Lechner M, Kuppert A. A review on tailored blanksproduction, applications and evaluation. Journal of Materials Processing Technology. 2014;214:151-64.

[5] Meyer A Ã, Wietbrock B, Hirt G. Increasing of the drawing depth using tailor rolled blanks-Numerical and experimental analysis. International Journal of Machine Tools and Manufacture. 2008;48:522-31.

[6] Eggertsen PA, Mattiasson K. Experiences from experimental and numerical springback studies of a semi-industrial forming tool. International journal of Material Forming. 2012;5:341-59.

[7] Aziz N, Bashah K, Muhamad N, Deros B, Zakaria A, Ashari S, et al. Multiregression modeling for springback effect on automotive body in white stamped parts. Materials \& Design. 2013;46:175-90. 
[8] Burchitz I. Springback, improvement of its predictability: Literature study report. (NIMR project MC1.02121). Enschede: Netherlands Institute for Metals Research. 2005.

[9] Fang Z, Jiang Z, Wei D, Liu X. Study on springback in micro V-bending with consideration of grain heterogeneity. International Journal of Advanced Manufacturing Technology. 2015;78:1075-85.

[10] Nie D, Lu Z, Zhang K. Hot V-bending behavior of pre-deformed pure titanium sheet assisted by electrical heating. International Journal of Advanced Manufacturing Technology In Press 2017. 2017.

[11] Aso T, lizuka T. FEM analysis of springback control with lump-punch penetration after V-bending. Journal of Physics: Conference Series: IOP Publishing; 2016. p. 032068.

[12] Yoshida T. Springback Problems in Forming of High-Strength Steel Sheets and Countermeasures, (103), Nippon Steel Technical Report. 2013:390-400.

[13] Abdullah AB, Samad Z. Effect of Bending Location on Springback via V-Bending Method. Australian Journal of Basic and Applied Sciences. 2015;9:15-20.

[14] Erdin ME, Atmaca A. Effects of Holding Force on the Springback Behavior of Annealed Aluminum Plates. Procedia Engineering. 2016;149:56-61.

[15] Kartik T, Rajesh R. Effect of Punch Radius and Sheet Thickness on Spring-back in V-die Bending. Advances in Natural and Applied Sciences. 2017;11:178-83.

[16] Yazdani A, Naseri R, Rahmati S. Investigation of springback of two-layer metallic sheet produced by explosive welding in U-die bending process. Journal of Engineering Research. 2017;5:187-206.

[17] Abdullah SA, Buang MS, Saedon J, Abdullah H. Design Parameters Selection Springback Effect in Air-V Bending Using Taguchi Approach on Advance High Strength Steel-DP590. Jurnal Teknologi (Sciences \& Engineering). 2015;76:6973.

[18] Suyuti MA, Nur R, Asmeati. The Influence of Punch Angle on the Spring Back during V-Bending of Medium Carbon Steel. Advanced Materials Research2015. p. 157-60.

[19] Panthi SK, Hora MS, Ahmed M. Artificial neural network and experimental study of effect of velocity on springback in straight flanging process. Indian Journal of Engineering and Material Sciences. 2016;23:159-64.

[20] Trzepiecinski T, HG. L. Effect of Computational Parameters on Springback Prediction by Numerical Simulation. Metals. 2017;7:380.

[21] Abdullah MA. Springback prediction in V-bending process using artificial neural netwok. Al-Qadisiyah Journal for Engineering Sciences. 2017;10:180-90.

[22] Paithankar SA, Varade BV. Springback Prediction Analytical Model for V-Bend Process. International Journal of Modern Trends in Engineering and Research. 2016;3:870-6.

[23] Panthi SK, Ramakrishnan N, Ahmed M, Singh SS, Goel MD. Finite element analysis of sheet metal bending process to predict the springback. Materials \& Design. 2010;31:657-62.

[24] Sutasn T, Pakkawat K. Analysis of bending mechanism and spring-back characteristics in the offset Z-bending process. The International Journal of Advanced Manufacturing Technology. 2016;85:2589-96.

[25] Trzepiecinski T, Lemu H. Prediction of springback in V-die air bending process by using finite element method. MATEC Web of Conferences: EDP Sciences; 2017. p. 03023. 
[26] Ling JS, Abdullah AB, Samad Z. Application of Taguchi method for predicting Springback in V-bending of aluminum alloy AA5052 strip. Journal of Scientific Research and Development. 2016;3:91-7.

[27] Karaagac İ. The Experimental Investigation of Springback in V-Bending Using the Flexforming Process. Arabian Journal of Science and Engineering. 2017;42:1853-64.

[28] Peng Q, Peng X, Wang Y, Wang T. Investigation on V-Bending and Springback of Laminated Steel Sheets. Journal of Manufacturing Science and Engineering. 2015;137:041002.

[29] Selvakumar N, Narayanasamy R. Experimental investigation of strain hardening behaviour of sintered aluminium preforms. Transactions of the Indian Institute of Metals. 2005;58:789-99.

[30] Ouakdi EH, Louahdi R, Khirani D, Tabourot L. Evaluation of springback under the effect of holding force and die radius in a stretch bending test. Materials \& Design. 2012;35:106-12.

[31] Karaagac İ. The evaluation of process parameters on springback in V-bending using the flexforming process. Materials Research. 2017;20:1291-9.

[32] Garcia-Romeu ML, Ciurana J, Ferrer I. Springback determination of sheet metals in an air bending process based on an experimental work. Journal of Materials Processing Technology. 2007;191:174-7.

[33] Abdullah AB, Samad Z. An experimental investigation of springback of AA6061 aluminum alloy strip via V-bending process. IOP Conference Series: Materials Science and Engineering: IOP Publishing; 2013. p. 012069.

[34] Zhang H. Springback characteristics in U-channel forming of tailor rolled blank. Acta Metallurgica Sinica. 2012;25:207-13. 